\title{
Efeitos da Espessura da Fita Metálica no Metal de Solda Utilizando Cavacos de Titânio Como Componentes do Fluxo em Arames Tubulares para a Formação de TiC
}

\author{
José Gedael Fagundes Júnior ${ }^{1}$ (D) , Alexandre Queiroz Bracarense ${ }^{2}$ (D) \\ ${ }^{1}$ Universidade Federal de Minas Gerais - UFMG, Programa de Pós-graduação em Engenharia Mecânica, Belo Horizonte, MG, Brasil. \\ ${ }^{2}$ Universidade Federal de Minas Gerais - UFMG, Departamento de Engenharia Mecânica, Belo Horizonte, MG, Brasil.
}

Como citar: Fagundes Junior JG, Bracarense AQ. Efeitos da espessura da fita metálica no metal de solda utilizando cavacos de titânio como componentes do fluxo em arames tubulares para a formação de TiC. Soldagem \& Inspeção. 2019;24:e2429. https://doi.org/10.1590/0104$9224 / S 124.29$

Resumo: Cavacos de titânio foram utilizados como componentes do fluxo em arames tubulares fabricados a partir da conformação e trefilação de fitas metálicas com espessuras diferentes. Os arames apresentaram diâmetros internos com dimensões diferentes afetando as taxas de preenchimento do fluxo. Para as mesmas condições de soldagem, os arames fabricados com as fitas de maior espessura promoveram maiores taxas de curto circuito na transferência metálica, enquanto que nas fitas finas houve uma transferência mista com curto circuito e globular. O processo se mostrou mais estável nos arames fabricados com a fita mais grossa. Apesar das micrografias evidenciarem áreas com maior presença de TiC, os carbonetos apresentaram uma distribuição bastante uniforme ao longo da solda. Nestas regiões nota-se que os carbonetos apresentaram partículas com tamanhos maiores e formato mais arredondado. Os valores de microdureza apresentaram relação direta com a oferta de titânio no fluxo.

Palavras-chave: Microdureza; Morfologia dos carbonetos; Reciclagem; TiC.

\section{Effects of Metallic Sheath Width on Weld Metal Microstructure by Applying Titanium Chips as Flux Compounds of Tubular Wire Aiming to React TiC}

\begin{abstract}
Titanium chips were used with flux components in tubular wires made from the conformation and drawing of metallic strips with different thicknesses. The wires showed internal diameters of different dimensions, affecting fluxes rates filling efficiency. For the same welding conditions, the wires made with the thicker tapes promoted higher short circuit rates in the metallic transfer, while in the thin tapes there was a mixed transfer with short circuit and globular. Stability of welding process was more notable by tubular wire made of the thicker tapes. The variation in the supply of titanium from the flow affected the morphology and size of the carbide particles considerably. The microhardness values presented a direct relation with the titanium supply in the flux.
\end{abstract}

Key-words: Microhardness; Carbide morphology; Recycling; TiC.

\section{Introdução}

A iminente extinção de alguns recursos naturais obriga o homem a desenvolver técnicas sustentáveis, como a reutilização e reaproveitamento dos resíduos gerados nas cadeias produtivas. A crescente demanda e acessibilidade econômica de implantes cirúrgicos e ortodônticos a base das ligas de titânio tem atraído grande interesse por parte da população. Para garantir melhor a aceitabilidade pelo organismo humano, a composição química de tais ligas apresenta o titânio como elemento majoritário, atingindo cerca de 90\% na liga Ti6Al4V (ASTM F136) e 99\% na liga F67 (titânio puro) [1-3]. Os graus de precisão dimensional e acabamento superficial de tais componentes fazem com que sua fabricação se dê pelos processos de usinagem, fazendo com que em média, cerca de $40 \%$ de material (volume) sejam removidos na forma de cavacos e estes por sua vez são descartados como sucata. Apesar de não ser reportado na literatura, dados internos de algumas empresas brasileiras, atuantes apenas na indústria de implantes ortodônticos chegam a gerar cerca de 5 toneladas por ano de cavacos na produção de implantes ortodônticos [4]. Este montante de resíduos apresenta baixo valor econômico quando comparado às ligas comerciais e deste modo podem seguramente ser beneficiado e reinserido na cadeia produtiva, acrescentando valores econômicos e tecnológicos ao produto. 
O titânio na forma de carbonetos, TiC, apresenta elevada estabilidade química, elevado ponto de fusão e elevada dureza (acima de $3.000 \mathrm{HV}$ ) [5-7]. Deste modo tem se tornado um grande atrativo na aplicação de superfícies onde são requeridas resistência aos mecanismos de desgaste. Para a formação dos carbonetos de titânio vários processos podem se aplicar uma vez que as condições de ligação dos elementos (Ti e C) sejam favoráveis para a nucleação e crescimento dos carbonetos.

A soldagem é um processo metalúrgico que envolve temperaturas elevadas na poça de fusão favorecendo diversos tipos de ligações e reações químicas dos elementos de ligas. Na literatura reporta-se diversos trabalhos visando a formação de carbonetos de titânio (TiC) a partir dos processos de soldagem [8-10]. Entretanto o titânio é adicionado ao fluxo na forma de ferro-ligas que geralmente apresentam graus de pureza nas faixas de $20 \%-60 \%$, e desta forma, promovem a redução de titânio em proporção no fluxo. Vários autores atribuem que a morfologia e o tamanho dos carbonetos são afetados pelo aporte térmico, taxas de solidificação e presença dos elementos químicos. É reportado na literatura pesquisa que investiga os efeitos do silício e do manganês na formação dos carbonetos de titânio. Carbonetos maiores e morfologia arredondada foram mais comuns nas soldas resultantes dos fluxos a base da adição de manganês [11]. Apesar de diversos autores investigarem a reação de carbonetos, a literatura carece de estudos que possam investigar os efeitos em quantidades do titânio sobre a microestrutura e a formação dos carbonetos.

Neste estudo, arames tubulares fabricados a partir de fitas metálicas com espessuras diferentes, apresentando cavacos provenientes da indústria de implantes ortodônticos como fonte de titânio foram utilizados para investigar o efeito do teor de titânio sobre a morfologia e tamanho das partículas de TiC.

\section{Metodologia}

Cavacos das ligas de titânio ASTM F136 - Grau IV (Ti6Al4V) disponibilizados pela empresa Neodent ${ }^{\circledR}$ foram submetidos a processos de limpeza, secagem, moagem, classificação dos finos e posteriormente utilizados com componentes do fluxo em arames do tipo MCAW, Figura 1.

O procedimento de limpeza se fez através da aplicação de banhos com imersão dos cavacos em soluções de detergente e água. Para a remoção do excesso de fluido de corte, incialmente os cavacos foram deixados imersos por pelos menos 48 horas em repetições de 2 ou 3 vezes. Dependendo do grau de contaminação dos cavacos esse processo foi repetido por mais vezes. Para uma limpeza mais eficiente, os cavacos foram submetidos a uma nova sequência de banhos ultrassônicos, ainda com a utilização da solução de limpeza e por fim apenas água promovendo o enxague dos cavacos. Em seguida os cavacos foram deixados em estufa para secagem.

A moagem dos cavacos se realizou em um moinho de panelas. Os finos obtidos na moagem foram classificados em peneiras, Figura 2a. Para componentes do fluxo foram utilizados os finos com tamanho nas faixas entre $400 \mu \mathrm{m}$ a $50 \mu \mathrm{m}$. Partículas com tamanhos maiores que $400 \mu \mathrm{m}$ retornaram a moagem. Partículas abaixo de $50 \mu \mathrm{m}$ foram destinadas a ensaios de identificação das fases e composição química.

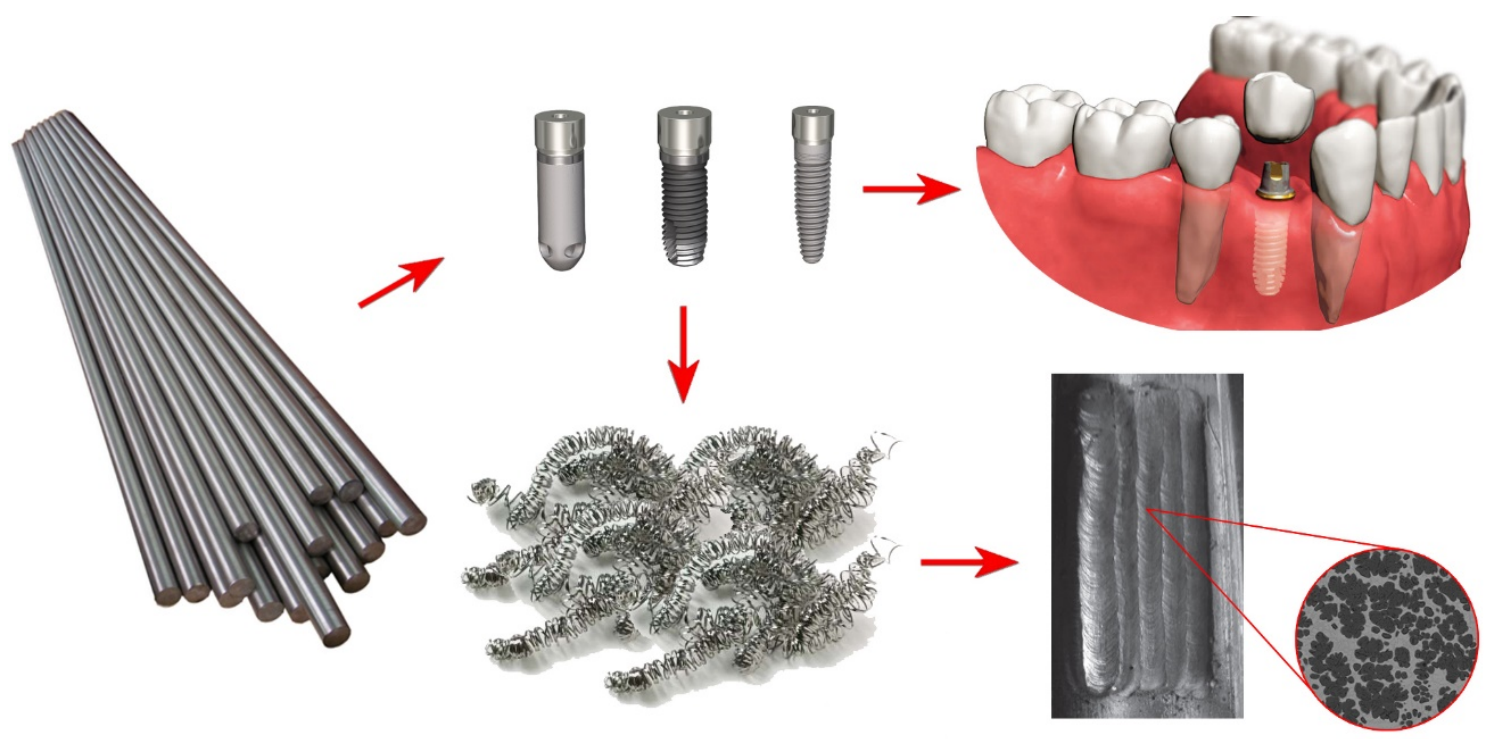

Figura 1. Procedência e beneficiamento dos cavacos de titânio para a formação de carbonetos.

A proporção de cavacos de titânio e grafite (carbono) para a formulação do fluxo foi determinada a partir dos cálculos estequiométricos através da massa relacionado com a quantidade de átomos de cada elemento para a formação de TiC ( 1 átomo 
de Ti para 1 átomo de C). Prevendo eventuais reações do carbono com o ferro presentes na fita metálica e metal de base, a

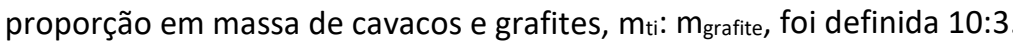

Os arames foram fabricados em um equipamento para a fabricação de arames experimentais pertencentes ao Laboratório de Robótica Soldagem e Simulação (LRSS - UFMG), Figura 2b, onde o processo se faz a partir da conformação de uma fita metálica em aço com teores percentuais de carbono abaixo de 0,08\%. Utilizou-se fitas metálicas com espessuras diferentes sendo uma apresentando as dimensões de $10 \times 0,5$ e outra $10 \times 0,3 \mathrm{~mm}$. O processo de fabricação dos arames ocorre através da conformação da fita metálica a partir da passagem entre roletes fazendo com que a fita assuma o formato de seção em $U$. Na sequência ocorre a alimentação do fluxo de modo contínuo através de uma correia transportadora com controle de vazão possibilitando uma distribuição padronizada do fluxo dentro do arame. Na sequência, a passagem da fita pelos roletes de fechamento faz com que o arame assuma o formato circular e assim sendo trefilado até o diâmetro requerido. Neste trabalho os arames foram produzidos com diâmetros de $2 \mathrm{~mm}$. A composição química nominal dos arames produzidos é apresentada na Tabela 1. Estes valores foram determinados levando em consideração a taxa de preenchimento do fluxo nos arames promovidas pelo diâmetro interno dos arames tubulares.

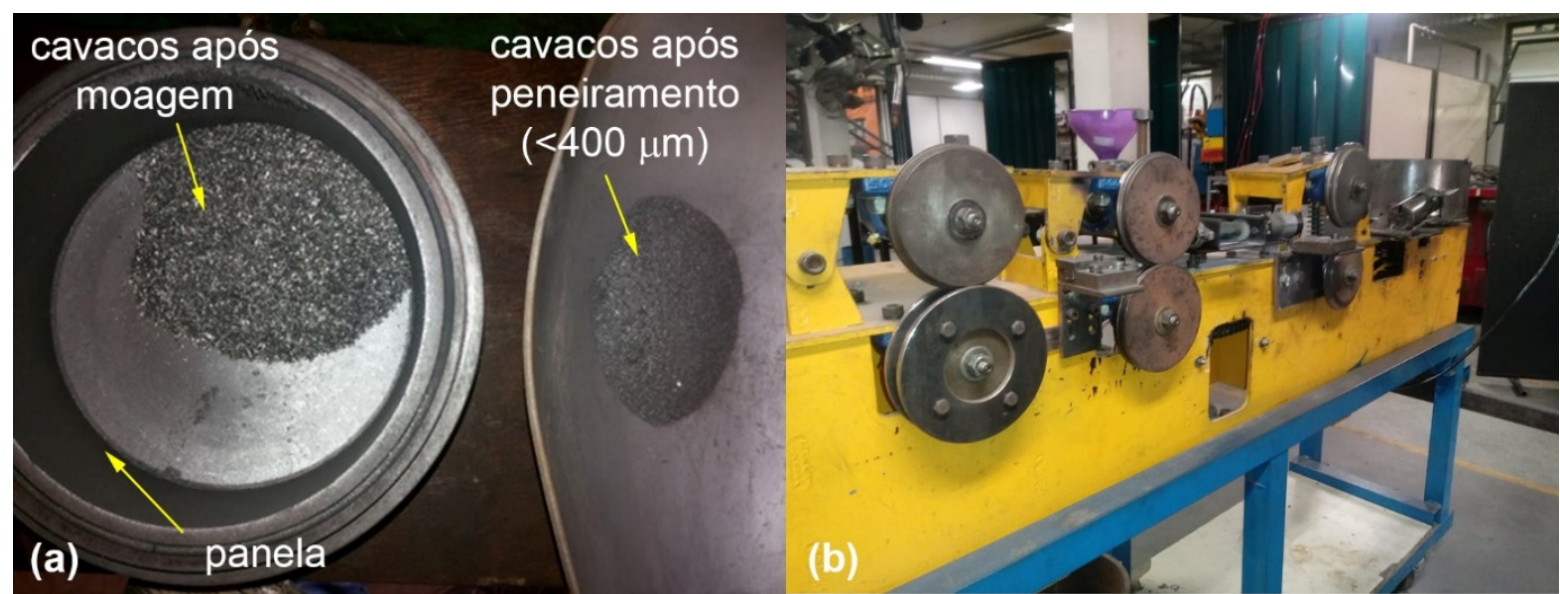

Figura 2. (a) Obtenção dos finos a partir da moagem dos cavacos de titânio; (b) Equipamento de fabricação dos arames tubulares.

Tabela 1. Composição química nominal dos arames tubulares.

\begin{tabular}{cccccccc}
\hline Arames Tubulares & Ti & C & Al & V & Outros & Fe \\
Fita $\mathbf{0 , 3 m m}$ & 11,8 & 4,0 & 0,8 & 0,5 & 0,4 & Bal. \\
Fita $\mathbf{0 , 5 m m}$ & 6,9 & 2,4 & 0,5 & 0,3 & 0,4 & Bal. \\
\hline
\end{tabular}

Fonte: Dados da pesquisa do autor.

A soldagem dos arames foi realizada a partir da utilização de uma fonte de soldagem Aristo MIG ESAB. Para controlar a velocidade de soldagem, a tocha foi fixada em um dispositivo acoplado em um carro portátil. Como metal de base utilizou-se chapas de aço SAE 1020 com dimensões de $150 \times 32 \times 10 \mathrm{~mm}$. Para evitar distorções durante a soldagem as chapas foram fixadas em um porta-amostra com travamento feito por parafusos, Figura 3a. Para verificar o comportamento dos parâmetros elétricos de soldagem, uma placa de aquisição de dados, foi integrada ao sistema. Os parâmetros de soldagem, Tabela 2, foram definidos a partir dos testes experimentais e mantidos constantes para todas as condições de soldagem. Para análises estatísticas foram depositados 03 cordões de solda para cada condição de espessura da fita metálica utilizada no arame.

As amostras foram retiradas dos cordões de solda, conforme apresentado na Figura 3b. Amostras $A^{\prime}$ e $B^{\prime}$ foram descartadas. Já as amostras A e B foram embutidas e preparadas por técnicas convencionais de metalografia com embutimento, lixamento e polimento. Para ataque químico foi utilizado NITAL 2\%. A microestrutura foi examinada por microscopia ótica a partir da captura em diferentes regiões das amostras. A microdureza foi realizada em um microdurômetro HV0,3, com o indentador sendo mantido por 15 segundos sobre a amostra. Para verificar as variações das microdurezas nas soldas, as medidas foram feitas em um espaçamento de $0,3 \mathrm{~mm}$ iniciando do topo da solda até atingir o metal de base além da ZTA. Para fins estatísticos a microdureza foi medida em uma sequência de 3 medições por amostra de seção dos cordões de solda. As amostras centrais $(C)$ foram retificadas na região superior do cordão e destinadas para ensaios de difração de raios-X. A identificação das fases foi realizada em um difratômetro equipado com um tubo de cobre. A identificação das fases se realizou a partir de utilização das fichas cristalográficas do Banco de Dados do ICSD [12].

O software ImageJ foi utilizado para fazer a verificação da morfologia e fração volumétrica dos TiC. O software SINAIS foi utilizado para fazer a análise dos sinais elétricos de soldagem. 


\section{Resultados e Discussão}

A moagem realizada através dos moinhos de panelas possibilitou uma melhor eficiência na obtenção dos finos, atingindo a granulometria desejada em uma quantidade de tempo bem menor, quando comparado a outras metodologias para a moagem de cavacos [13]. Os ensaios de DRX indicaram que as fases presentes nos cavacos moídos foram idênticas aquelas das barras de titânio conforme a liga ASTM F-136 comprovando que não houve formação de óxidos de titânio, indicando que o processo de moagem pelo moinho de panelas pode perfeitamente ser utilizado na moagem dos cavacos.
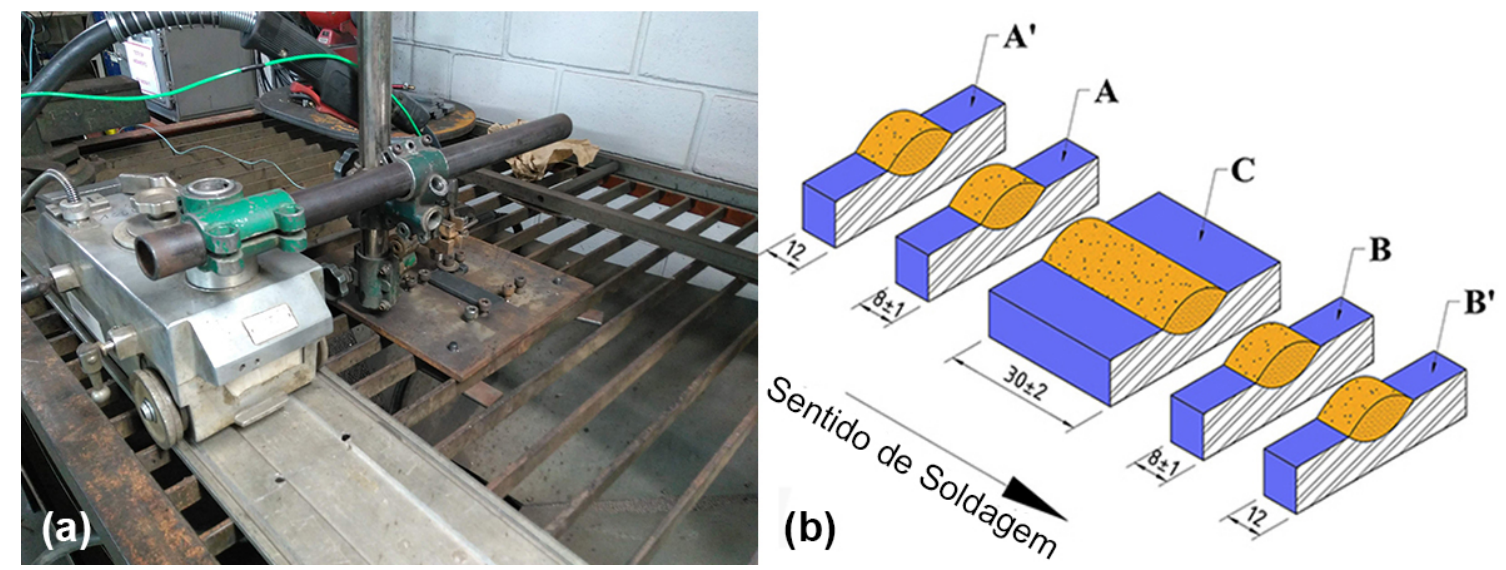

Figura 3. (a) Realização de soldagem; (b) Corte das amostras nos cordões de solda.

Tabela 2. Parâmetros de soldagem ajustados na fonte de soldagem.

\begin{tabular}{cc}
\hline Parâmetros & Valores \\
Tensão $(\mathrm{V})$ & 25 \\
Velocidade do Arame $(\mathrm{m} / \mathrm{min})$ & 4 \\
Velocidade de Soldagem $(\mathrm{mm} / \mathrm{min})$ & 300 \\
Vazão do Gás $(\mathrm{I} / \mathrm{min})$ & 18 \\
Polaridade & DCEP \\
DBCP* $(\mathrm{mm})$ & 30 \\
\hline
\end{tabular}

*Distância bico de contato a peça.

Os arames fabricados apresentaram em ambos os casos fechamento do tipo de topo e com taxas de eficiência do preenchimento do fluxo (relação entre a massa de fluxo pela massa de arame), com valores de 10,7\% e 17,1\% para os arames de com espessura de $0,5 \mathrm{~mm}$ e $0,3 \mathrm{~mm}$, respectivamente. A fita com espessura menor promoveu a formação de um arame tubular com diâmetro interno maior, possibilitando maiores quantidades de fluxo no enchimento do arame representado pela taxa de preenchimento do fluxo no arame, Figura 4. O fato de os carbonetos serem formados a partir dos elementos presentes no fluxo, nota-se que as soldas formadas com os arames que apresentaram maiores taxas de preenchimento do fluxo promoveram a formação de maiores frações volumétricas de carbonetos.

Para atingir o diâmetro externo de $2 \mathrm{~mm}$, a tração aplicada no processo de trefilação promoveu uma redução na espessura

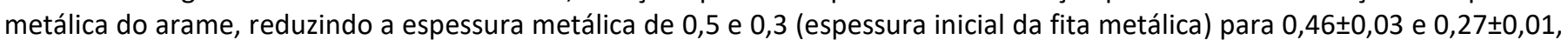
respectivamente. Os arames fabricados com a fita de $0,5 \mathrm{~mm}$ apresentaram desalinhamentos na trajetória do arame no percurso entre o bico de contato e a peça, quando comparados com os arames da fita com espessura de $0,3 \mathrm{~mm}$. Utilizando um software de medição, nota-se um desalinhamento de $1,3 \mathrm{~mm}$ com o centro do bocal e inclinação da reta tangente a curvatura do arame igual a $8^{\circ}$ para os arames com fita de $0,5 \mathrm{~mm}$, Figura 5 a, enquanto que para as fitas de 0,3 $\mathrm{mm}$ o desalinhamento foi de $0,5 \mathrm{~mm}$ e inclinação de $2^{\circ}$, Figura $5 \mathrm{~b}$. Medidas de microdureza nas seções transversais e longitudinais da fita metálica, antes e após a conformação dos arames tubulares, indicaram uma variação significativa nos valores de microdureza, Figura 6 , principalmente nos arames fabricados com fita grossa, como resultado do encruamento da fita promovido pelo processo de trefilação dos arames tubulares. Como ambos os arames foram tracionados e enrolados em um tambor com mesmo diâmetro (280 mm), a arame fabricado com a fita de 0,5 $\mathrm{mm}$ apresentou maiores deformações plásticas como efeito da espessura da fita e do encruamento resultando neste desalinhamento do arame entre o bico de contato e o metal de base. 

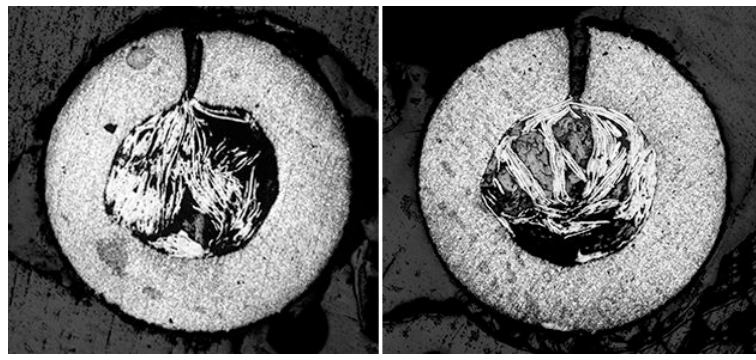

Figura 4. Seção dos arames tubulares.
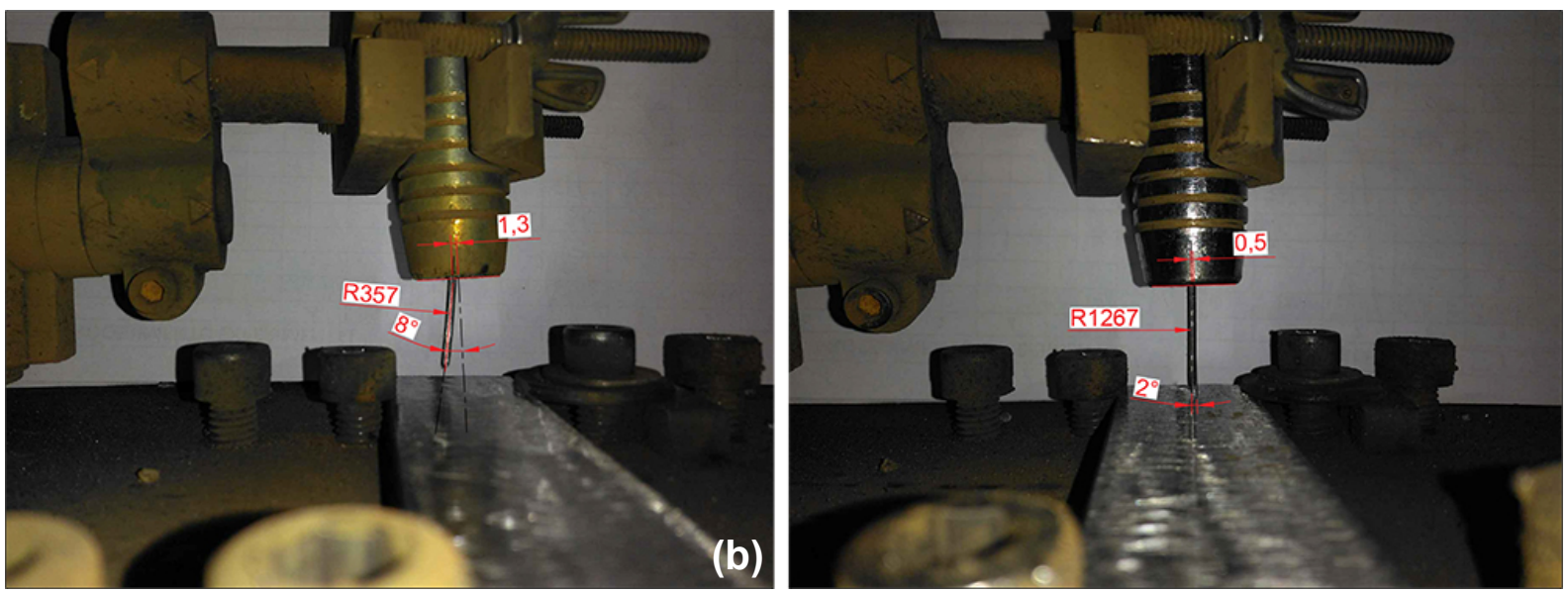

Figura 5. Características dos arames tubulares. (a) Arame com a fita de espessura igual a 0,5 mm; (b) Arame com a fita de espessura igual a $0,3 \mathrm{~mm}$.
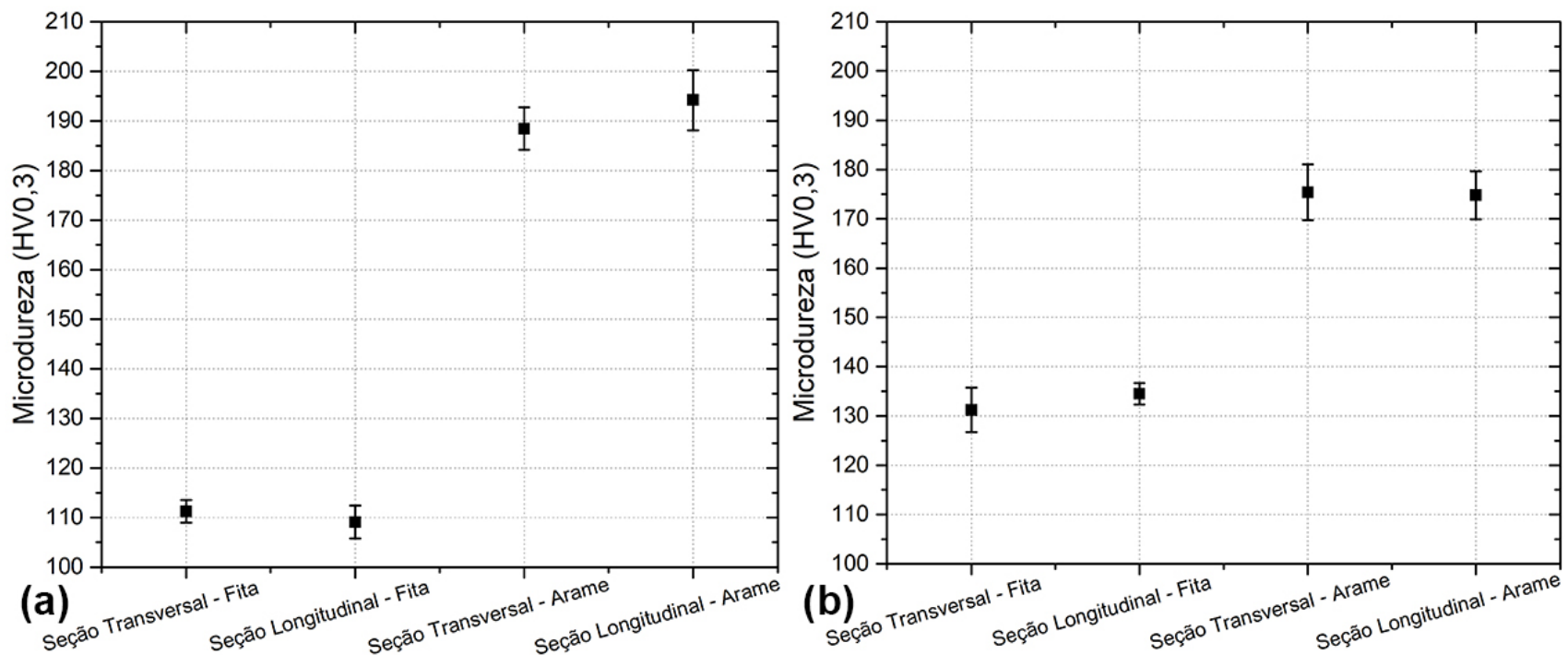

Figura 6. Variação da dureza na seção transversal e longitudinal das fitas metálicas e dos arames tubulares. (a) Fita 0,5 mm; (b) Fita 0,3 mm.

A transferência metálica apresentou comportamento majoritariamente por curto-circuito em ambos os casos. Para as condições de soldagem utilizando os arames tubulares com fita de 0,3 $\mathrm{mm}$ e 0,5 mm, considerando as áreas das seções dos arames tubulares, os valores de densidade de corrente apresentaram valores médios de 169,86 $\pm 3,63 \mathrm{~A} / \mathrm{mm}^{2}$, Tabela 3. Logo, a elevação da corrente nos arames com fita grossa, Figura 7, pode ser atribuído ao fato de que o aumento na área da seção do arame, implica a necessidade de uma maior energia para promover a fusão, em função do aumento da quantidade de material, uma vez que a quantidade de energia por unidade de área necessária para ocorrer a fusão do arame seja a princípio constante. Em adição, a elevação da corrente promoveu maiores energias de soldagem no processo, Figura 8. 
Tabela 3. Densidade da corrente de soldagem em função da espessura da fita metálica.

\begin{tabular}{ccc}
\hline Parâmetros & Fita $\mathbf{0 , 5} \mathbf{~ m m}$ & Fita $0,3 \mathrm{~mm}$ \\
Diâmetro externo do arame $(\mathbf{m m})$ & 2,00 & 2,00 \\
Diâmetro interno d arame $(\mathbf{m m})$ & 1,08 & 1,46 \\
Área da seção transversal $\left(\mathbf{m m}^{2}\right)$ & 2,26 & 1,47 \\
Corrente média $(\mathbf{A})$ & 374,02 & 251,91 \\
Densidade da corrente $\left(\mathbf{A} / \mathrm{mm}_{\mathbf{2}}\right)$ & 168,06 & 171,67 \\
\hline
\end{tabular}

Transferências metálicas por curto circuito apresentam maiores dispersões dos valores médios de tensão quando comparados aos demais tipos de transferências. Deste modo, a determinação da estabilidade do processo não é definida com segurança analisando apenas o desvio dos valores médios da tensão. O coeficiente de variação (CV) é utilizado para verificar a estabilidade do processo, levando em consideração os valores da tensão em arco aberto [14]. Os baixos CV das soldas fabricadas com arames tubulares de fitas grossas, Figura 8, indicam comportamento mais estáveis do arco elétrico, que podem ser atribuídos a uma diminuição do fluxo contendo titânio e carbono e um aumento da quantidade de ferro, proveniente da fita metálica.

Soldas exploratórias realizadas com arame fabricado com fita fina $(0,3 \mathrm{~mm})$ e fluxo contendo apenas de cavacos de titânio apresentaram CV com valores médios de $5 \%$ semelhantes aos valores resultantes com arames tubulares provenientes da fita grossa. Deste modo acredita-se que as alterações na estabilidade do arco estejam sendo provocadas pela redução do teor de carbono no fluxo que por sua vez apresenta elevado potencial de ionização (2352,6 kJ/mol) comparados ao ferro (1561,9 kJ/mol) e ao titânio (1309,8 kJ/mol). Redução da estabilidade do arco podem ser causadas por elevados potenciais de ionização dos elementos presentes no fluxo [15].
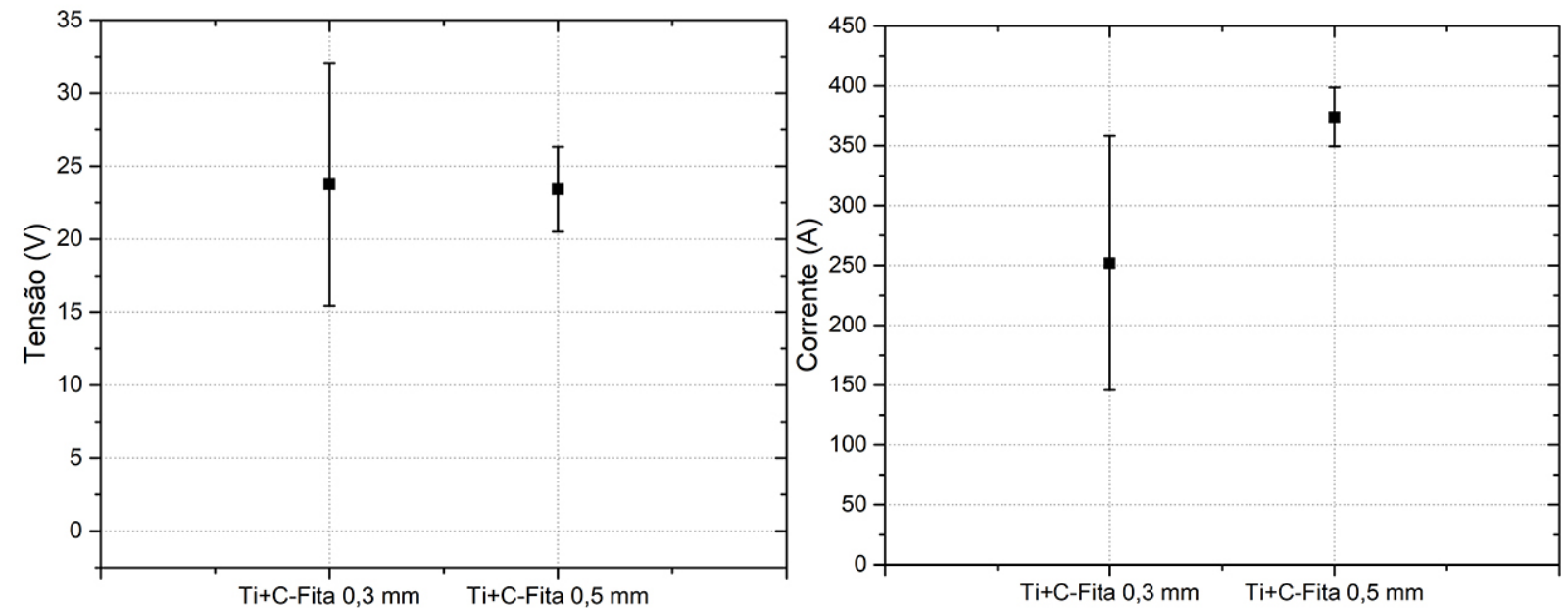

Figura 7. Comportamento da tensão e corrente durante a soldagem dos arames com espessuras diferentes.
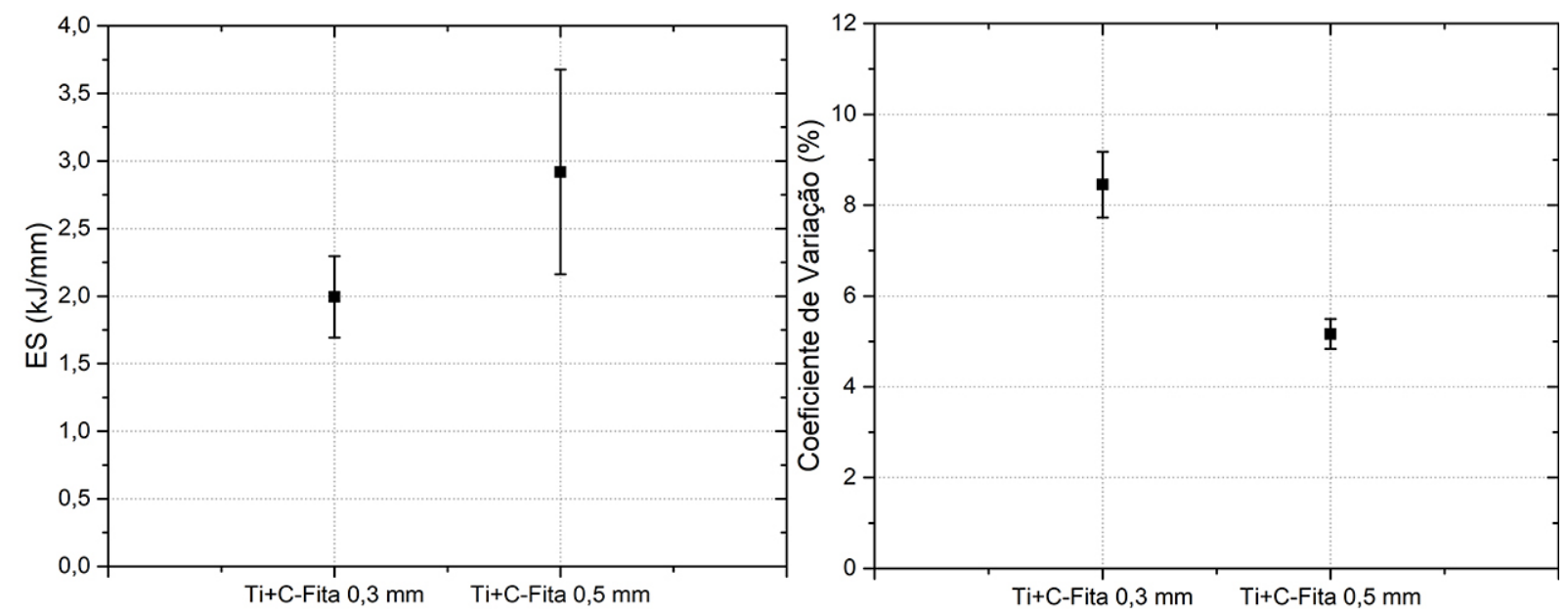

Figura 8. Energia de soldagem e coeficiente de variação na soldagem dos arames tubulares. 
Os cordões apresentaram uma superfície atípica dos processos de soldagem com arames tubulares, gerando uma aparência bastante áspera e com rugosidade elevada, Figura 9. Há ainda uma grande concentração de poros nos topos dos cordões, entretanto nota-se boa coalescência entre a solda e o metal de base, uma vez que os cordões não apresentaram trincas e nem falta de fusão. A presença de poros e os aspectos superficiais podem estar ocorrendo devido uma elevada viscosidade da poça de fusão promovida pelo titânio, uma vez que foi observado que as soldas a base de titânio puro como fluxo, apresentou comportamento semelhante. Soldas de revestimento duro a base de Fe-Cr-C com a adição de titânio tem apresentado aspectos superficiais com elevada rugosidade comparadas aquelas sem a adição de titânio [16]. Desta forma, a adição de elementos aplicados no fluxo para reduzir a viscosidade da poça de fusão podem melhorar estes aspectos. A literatura mostra que a adição de fluorita $\left(\mathrm{CaF}_{2}\right)$ no fluxo pode promover uma melhor fluidez da poça de fusão [17].

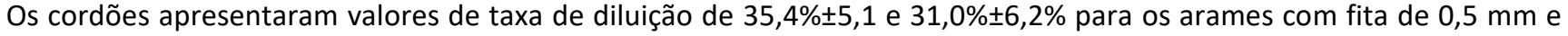
$0,3 \mathrm{~mm}$, respectivamente, Figura 10. Teste de significância por ANOVA, Figura 11, indicou que considerando o nível de 0,05, não há evidências de que as médias dos valores de diluição apresentem diferenças significantes para os arames tubulares fabricados com fita de $0,5 \mathrm{~mm}$ e $0,3 \mathrm{~mm}$. Os arames fabricados com as fitas grossas formaram cordões com seções maiores em virtude da maior oferta de massa por unidade de comprimento do arame.

As curvas geradas pelos difractogramas, Figura 12, confirmaram a formação de carbonetos de titânio no metal de solda. Os picos de difração da ferrita e martensita apresentam posições muito próximas. Indentações de microdureza apontada na matriz da solda tem indicado valores de dureza indicando possivelmente a formação destes dois constituintes na matriz do metal de solda.

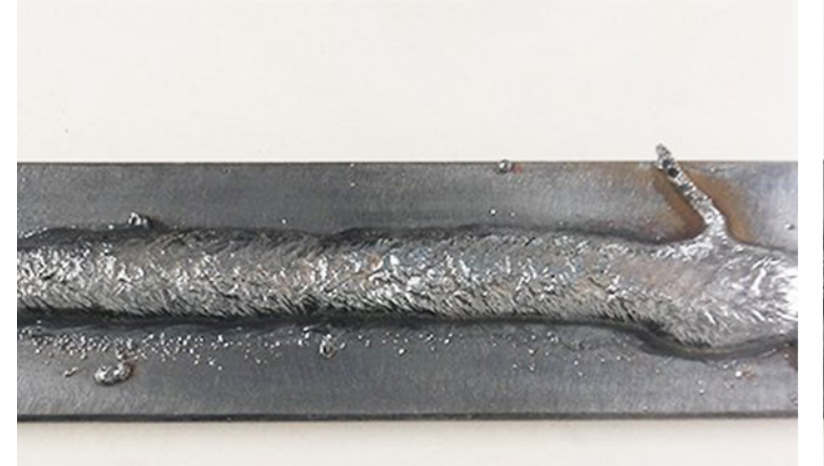

(a)

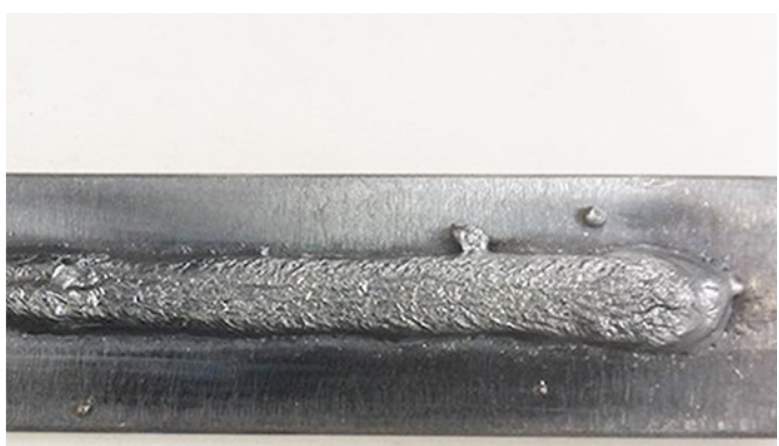

$\overline{10 \mathrm{~mm}}$ $\overline{10 \mathrm{~mm}}$ (b)

Figura 9. Topografia dos cordões de solda. (a) Arame com fita de 0,5 mm; (b) Arame com fita de 0,3 mm.
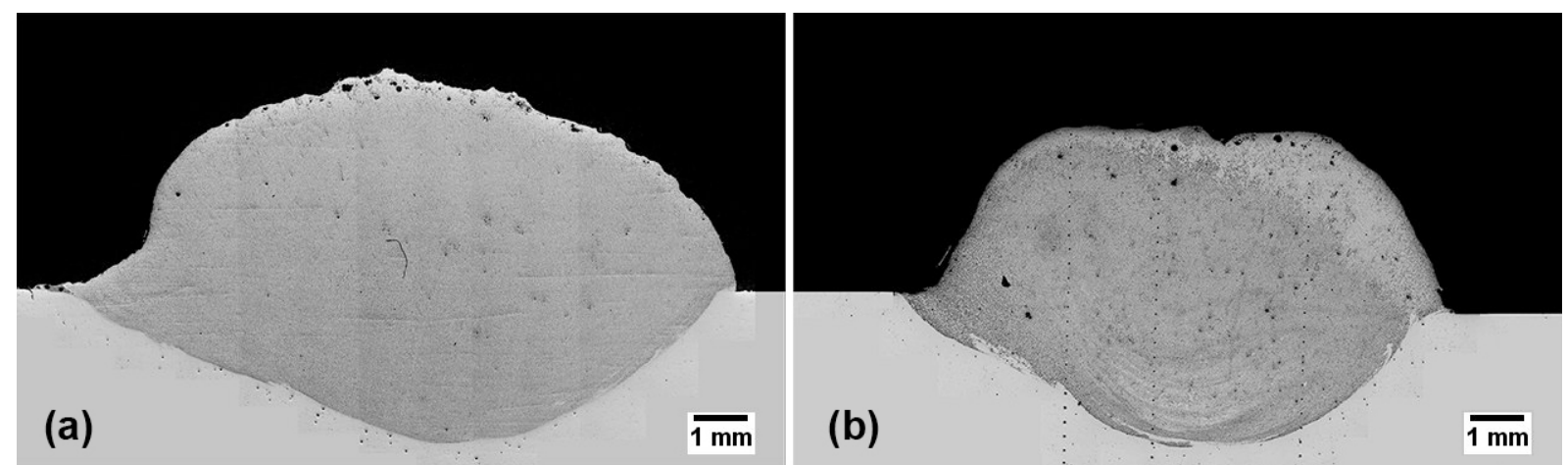

Figura 10. Aparência dos cordões de solda. (a) Arame com fita de 0,5 mm; (b) Arame com fita de 0,3 mm. 
ANOVA

\begin{tabular}{|r|c|c|c|c|c|}
\hline $\begin{array}{c}\text { Fonte de } \\
\text { Variação }\end{array}$ & $\begin{array}{c}\text { Graus de } \\
\text { Liberdade }\end{array}$ & $\begin{array}{c}\text { Soma dos } \\
\text { Quadrados }\end{array}$ & $\begin{array}{c}\text { Média dos } \\
\text { Quadrados }\end{array}$ & F & Prob>F \\
\hline Modelo & 1 & 45,95983 & 45,95983 & 1,37447 & 0,27477 \\
\hline Erro & 8 & 267,50547 & 33,43818 & & \\
\hline Total & 9 & 313,4653 & & & \\
\hline
\end{tabular}

Hipótese Nula: A média de todos os níveis são iguais.

Hipótese Alternativa: A média de um ou mais níveis são diferentes.

No nível de 0,05 , a média populacional não apresenta diferenças significantes.

\section{Estatística}

\begin{tabular}{|c|c|c|c|}
\hline $\mathbf{R}$ & $\begin{array}{c}\text { Coeficiente de } \\
\text { Variação }\end{array}$ & $\begin{array}{c}\text { Raiz média dos } \\
\text { quadrados }\end{array}$ & $\begin{array}{c}\text { Média dos } \\
\text { Dados }\end{array}$ \\
\hline 0,14662 & 0,17634 & 5,78258 & 32,79129 \\
\hline
\end{tabular}

Figura 11. Resultados do teste de significância (ANOVA).

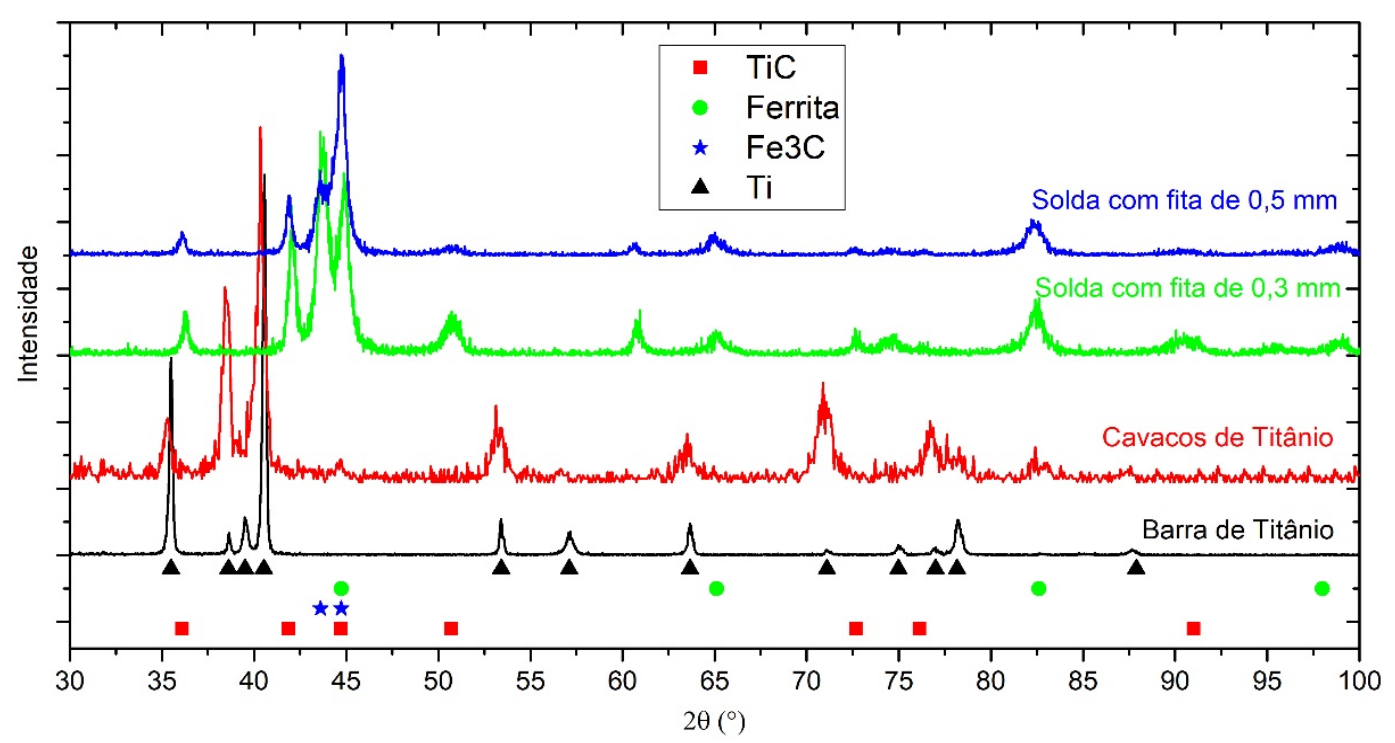

Figura 12. Curvas dos difractogramas realizados nas amostras.

A formação dos carbonetos de titânio foi evidenciada de forma distribuída e uniforme na microestrutura de todos os cordões depositados a partir da microscopia ótica, Figura 13. Os carbonetos apresentaram morfologia preferencialmente e multifacetada e algumas regiões arredondadas. A literatura reporta através do trabalho de diversos autores que para sistemas similares do tipo Fe-Ti-C, a sequência de solidificação envolve uma nucleação heterogênea de TiC através de uma inclusão ou discordância e deste modo podem assumir morfologia arredondada para os carbonetos primários e multifacetadas para os secundários. Na sequência apresentam crescimento radial e dendrítico regido pelas frentes de solidificação dos carbonetos [18-20].

Os arames fabricados com fitas de maior espessura $(0,5 \mathrm{~mm})$ apresentaram taxas de preenchimento do fluxo reduzidas quando comparadas as fitas finas $(0,3 \mathrm{~mm})$ e deste modo tem consequentemente apresentado uma oferta de titânio menor na solda. A partir deste trabalho, supõe-se que mantidas as condições de soldagem, maiores ofertas de titânio irão apresentar uma maior facilidade de formar TiC mais grosseiros e arredondados. Conforme indicado na Figura 13b, as regiões com maiores densidades de TiC (principalmente no centro de um conjunto de carbonetos) apresentaram uma tendência a formar partículas mais arredondadas quando comparada as regiões periféricas onde se tem grandes áreas da matriz ferrítica. Análises de EDS (MEV) têm indicado que carbonetos massivos e com morfologia arredondada tem preferencialmente se formado em regiões onde a matriz apresentou teores de titânio elevado, Figura 13c e Figura 13d.

A fração volumétrica dos carbonetos, apresentaram valores médios aproximados de $10,4 \%$ e $25,4 \%$ para os arames fabricados com as fitas em espessura de $0,5 \mathrm{~mm}$ e $0,3 \mathrm{~mm}$, respectivamente. Como consequência de maiores taxas de preenchimento de fluxo nos arames, formação de partículas de carbonetos e frações volumétricas maiores, nota-se que os arames fabricados com fita metálica de espessura menor promoveram maiores valores de dureza, Figura 14. A distribuição dos 
carbonetos e o tipo de matriz formada nos bolsões interdendríticos são fundamentais para os valores de dureza ao fato de que indentações realizadas em regiões desprovida dos carbonetos e matriz ferrítica tendem a apresentar baixa dureza enquanto que regiões ricas em carbonetos combinadas com uma matriz composta de martensita irão apresentar valores de dureza mais elevada. A baixa dispersão nos valores medidos pode ser atribuída à distribuição uniforme dos carbonetos na solda ao fato de que o valor de dureza é resultado da região atingida pelo indentador.
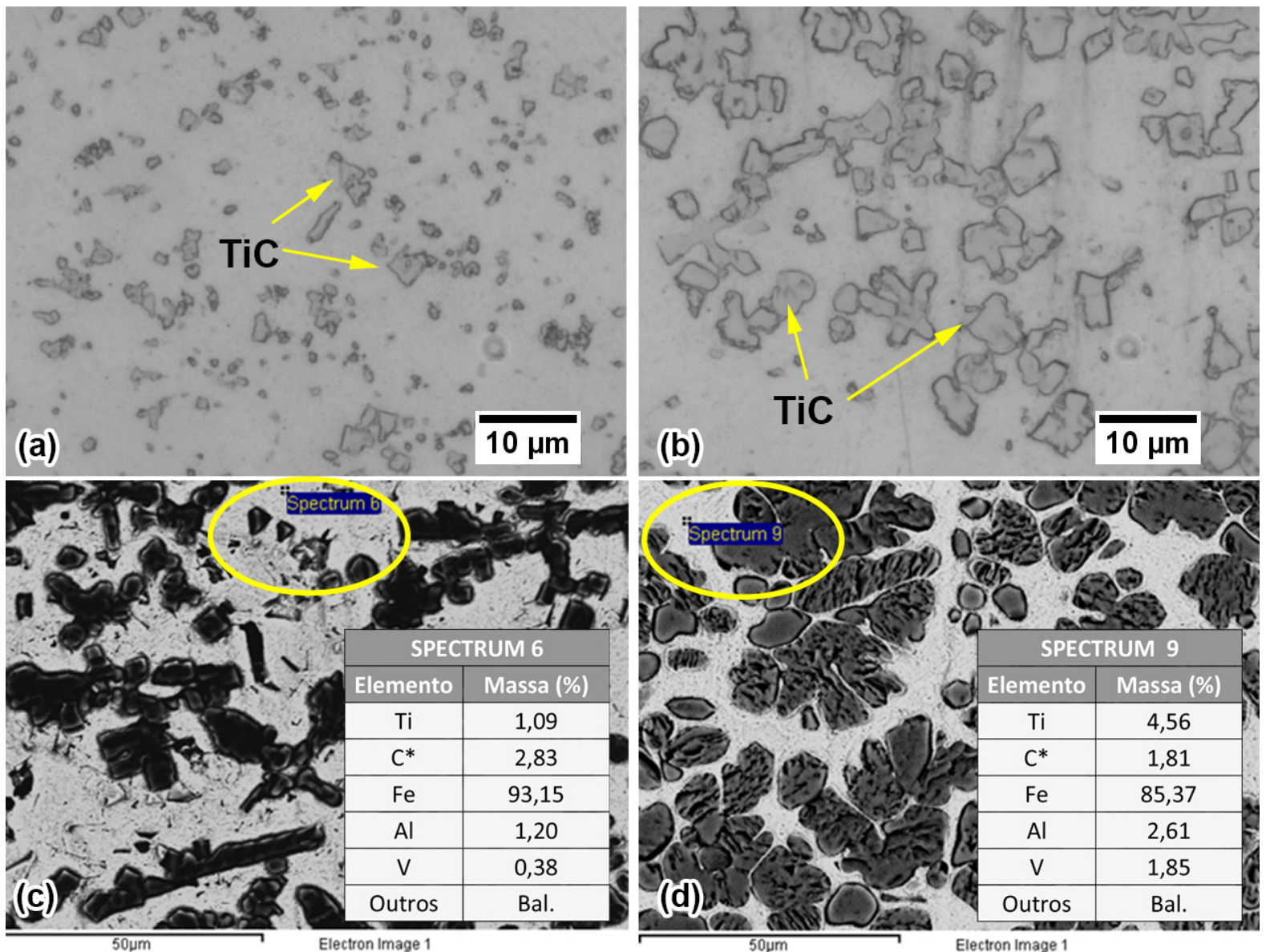

Figura 13. Microestrutura dos cordões de solda. (a) Solda com arames fabricados nas fitas de 0,5 mm; (b) Solda fabricada nos arames de 0,3 mm; (c) EDS em matriz com formação de TiC facetados; (d) EDS em matriz com formação de TiC arredondados. *Elementos com números atômicos baixo podem apresentar valores imprecisos em análises de EDS.
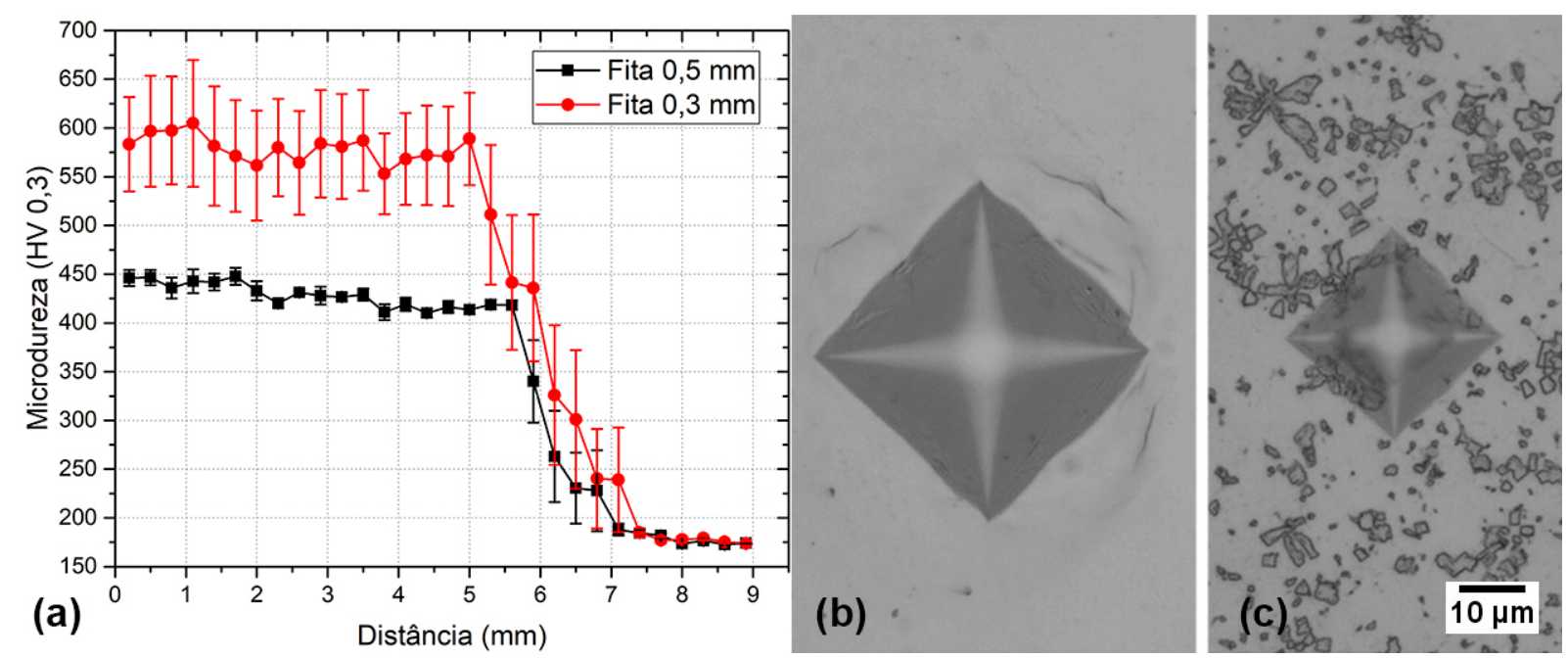

Figura 14. Análises de microdureza nas soldas. (a) Dureza ao longo dos cordões; (b) Indentações realizadas no metal de base; (c) Indentações no metal de solda. 


\section{Conclusão}

A utilização de cavacos de titânio como fluxos de soldagem em arames tubulares apresentou comportamentos satisfatórios quanto a formação de carbonetos na microestrutura do metal depositado. O metal depositado apresentou ótima coesão com o metal de base e elevação dos valores de durezas.

Os carbonetos apresentaram preferencialmente morfologia facetada em todas as condições. Entretanto, as soldas realizadas a partir da deposição dos arames com fita fina, como efeito das maiores taxas de preenchimento do fluxo apresentaram regiões com morfologia levemente arredondada. Indicando que a quantidade de titânio na microestrutura esteja afetando a geometria dos carbonetos.

A espessura da fita metálica utilizada na fabricação dos arames se mostrou como uma variável significante do processo afetando a soldabilidade e a microestrutura das soldas depositadas.

A presença de algumas descontinuidades como poros e rugosidade no acabamento superficial dos cordões, pode estar sendo promovida por deficiência na fluidez da poça de fusão. A adição de outros elementos no fluxo pode melhorar estes comportamentos.

Os resultados e as conclusões obtidas no presente trabalho apresentaram resultados semelhantes aqueles reportados na literatura onde foram utilizados pós comerciais de titânio indicando a viabilidade da aplicação dos cavacos de titânio como matérias primas para consumíveis de soldagem. Entretanto para uma produção em larga escala o processo de moagem deverá ser aprimorado para uma melhor eficiência.

\section{Agradecimentos}

Os autores agradecem a empresa Neodent pelo fornecimento dos cavacos de titânio utilizados neste trabalho, aos Departamentos de Engenharia Metalúrgica e Materiais (DEMET) e de Minérios (DEMIN), ambos UFMG, pela disponibilização dos recursos de Caracterização Microestrutural (DRX) e Moagem. Ao apoio financeiro da CAPES durante a realização deste trabalho.

\section{Referências}

[1] Jemat A, Ghazali MJ, Razali M, Otsuka Y. Surface modifications and their effects on titanium dental implants. BioMed Research International. 2015;2015:791725. http://dx.doi.org/10.1155/2015/791725. PMid:26436097.

[2] Markhoff J, Krogull M, Schulze C, Rotsch C, Hunger S, Bader R. Biocompatibility and inflammatory potential of titanium alloys cultivated with human osteoblasts, titanium alloys cultivated with human osteoblasts. Materials. 2017;10(1):52. http://dx.doi.org/10.3390/ma10010052. PMid:28772412.

[3] American Society for Testing and Materials. ASTM F 136-02A: standard specification for wrought titanium-6aluminum-4vanadium eli (extra low interstitial) alloy for surgical implant applications (unsr56401). West Conshohocken: ASTM; 2002. p. 1-4.

[4] NEODENT. A Straumann group brand. 2019 [acesso em 20 ago. 2019]. Disponível em: https://www.straumann.com/neodent.html

[5] Bulloch JH, Henderson JL. Some considerations of wear and hardfacing materials. International Journal of Pressure Vessels and Piping. 1990;46(3):251-267. http://dx.doi.org/10.1016/0308-0161(91)90073-B.

[6] Holleck H. Material selection for hardfacing. Journal of Vacuum Science and Technology. 1986;3:2660-2669.

[7] Henderson L, Bulloch JH. Alloy classification of hardfacing materials. International Journal of Pressure Vessels and Piping. 1991;47(2):127-158. http://dx.doi.org/10.1016/0308-0161(91)90096-K.

[8] Emamian A, Corbin SF, Khajepour A. Effect of laser cladding process parameters on clad quality and in-situ formed microstructure of FeTiC composite coatings. Surface and Coatings Technology. 2010;205(7):2007-2015. http://dx.doi.org/10.1016/j.surfcoat.2010.08.087.

[9] Emamian A, Corbin S, Khajepour A. The influence of combined laser parameters on in-situ formed TiC morphology during laser cladding. Surface and Coatings Technology. 2011;206(1):124-131. http://dx.doi.org/10.1016/j.surfcoat.2011.06.062.

[10] Wang X, Han F, Liu X, Qu S, Zou Z. Microstructure and wear properties of the Fe-Ti-V-Mo-C hardfacing alloy. Wear. 2008;265(5-6):583589. http://dx.doi.org/10.1016/j.wear.2007.12.001.

[11] Gallo SC, Alam N, O'Donnell R. In-situ synthesis of titanium carbides in iron alloys using plasma transferred arc welding. Surface and Coatings Technology. 2013;225:79-84. http://dx.doi.org/10.1016/j.surfcoat.2013.03.019.

[12] Inorganic Crystal Structure Database. Germany: ICSD; 2019 [acesso em 20 abr. 2019]. Disponível em: https://www.fizkarlsruhe.de/en/produkte-und-dienstleistungen/inorganic-crystal-structure-database-icsd

[13] Fagundes JG Jr, Ventrella VA, Gallego . Reciclagem de cavacos de titânio para a deposição de revestimentos duros por soldagem. Soldagem e Inspeção. 2015;20(1):117-127. http://dx.doi.org/10.1590/0104-9224/SI2001.12.

[14] Menezes PHR, Pessoa ECP, Bracarense AQ. Comparison of underwater wet welding performed with silicate and polymer agglomerated electrodes. Journal of Materials Processing Technology. 2019;266:63-72. http://dx.doi.org/10.1016/j.jmatprotec.2018.10.019. 
[15] Farias JP, Scotti A. Influência da composição do revestimento na estabilidade de eletrodos básicos. Revista Tecnologia. 1986;7(7):55-60.

[16] Lima AC, Ferraresi VA. Analysis of wear resistance of hardfacing applied by welding in sugarcane shredder. Soldagem \& Inspeção. 2009;15:94-102.

[17] Kil W, Shin M-J, Bang K-S. Effects of fluoride in the flux on hydrogen content in weld metal and operating behavior in FCAW-S. Journal of Welding and Joining. 2017;35(5):65-70. http://dx.doi.org/10.5781/JWJ.2017.35.5.9.

[18] Karantzalis AE, Lekatou A, Georgatis E, Arni Z, Dracopoulos V. Solidification observations of vacuum arc melting processed Fe-Al-TiC composites TiC precipitation mechanisms. Materials Characterization. 2011;62(12):1196-1204. http://dx.doi.org/10.1016/j.matchar.2011.10.009.

[19] Karantzalis AE, Lekatou A, Tsirka K. Solidification observations and sliding wear behavior of vacuum arc melting processed Ni-Al-TiC composites. Materials Characterization. 2012;69:97-107. http://dx.doi.org/10.1016/j.matchar.2012.04.013.

[20] Sahoo $P$, Koczak M. Analysis of in situ formation of titanium carbide in aluminum alloys. Materials Science and Engineering A. 1991;144(1-2):37-44. http://dx.doi.org/10.1016/0921-5093(91)90207-4. 